\title{
Monitoring eye movements during the learning of noun-pairs involving four combinations of stimulus and response concreteness-abstractness
}

P. D. McCORMACK, W. E. FINGAS, KATHY M. HAYCOCK AND T. E. MOORE, DEPARTMENT OF PSYCHOLOGY, CARLETON UNIVERSITY, Ottawa, Canada

Eye movements were monitored as Ss learned pairs of nouns where concreteness-abstractness $(C-A)$ was manipulated on the stimulus and response sides. Each of four groups was given four study-test trials on one of four 7-pair lists: CC, CA, AC, AA. The learning of groups $C C, C A$, and $A C$ was superior to that of group $A A$. More eye movements were observed during the learning of lists with concrete response terms, and response viewing predominated during the learning of lists in which the stimulus was concrete. These findings were discussed in the light of Paivio's recent work.

When Ss are required to learn pairs of nouns where concreteness-abstractness (C-A) is manipulated on the stimulus and response sides, concreteness has been demonstrated to have a facilitating effect, this being most pronounced on the stimulus side (Paivio, 1965; Paivio \& Yuille, 1966; Paivio, Yuille, \& Smythe, 1966; Yuille \& Paivio, in press). Paivio (1967) accounts for these findings by postulating that the learning of paired-associates (PA) can be mediated by sensory images, and that these imaginal mediators are aroused in direct relation to the degree of concreteness of stimuli and responses. The image-arousing value of the stimulus member is of particular importance, however, since the stimulus is presented alone on recall trials and, therefore, serves as a cue that presumably reinstates the mediating image.

A series of verbal learning investigations (e.g., McCormack \& Haltrecht, 1966) in which eye movements were photographed has provided support for the position that the learning of PA lists is a two-stage process (Underwood, Runquist, \& Schulz, 1959) involving response consolidation and $S-R$ hook-up. These studies have used nonsense-syllable materials of middle meaningfulness $\left(\mathrm{m}^{\prime}\right)$ (Noble, 1961) and the study-test method. As learning progressed, response viewing time decreased while time spent viewing the stimulus increased. The Ss also evidenced a predominant behavior pattern of looking first to the stimulus and then to the response during early learning trials, but later in learning exhibited a pattern of S-R-S viewing. The purpose of the present study was to monitor eye movements in a Paivio-type situation employing $\mathrm{CC}, \mathrm{CA}, \mathrm{AC}$, and $\mathrm{AA}$ lists and to examine the eye movement and fixation functions with respect to their similarity, if any, to those obtained from learning situations involving nonsense-syllables, as well as to determine whether these data reveal any evidence for the notion of imaginal mediation.

Subjects and Apparatus. The Ss were 60 students of introductory psychology, eight males and seven females being randomly assigned to each of the four conditions. The $\mathrm{C}$ and $\mathrm{A}$ items were chosen from a set of 925 nouns (Paivio, Yuille, \& Madigan, 1968) for which concreteness (C), imagery (I), meaningfulness $(\mathrm{m})$ and Thorndike-Lorge $(\mathrm{F})$ values are available. The $\mathrm{C}$ terms had mean $C$ and I values of 6.61 and 6.33 , respectively, whereas the $A$ terms had mean scale values of 2.40 for $C$ and 3.22 for $I$. The $m$ values for the $\mathrm{C}$ and $\mathrm{A}$ nouns were 5.92 and 5.62 , respectively, with the $\mathrm{F}$ values also being equated as closely as possible. Each list was projected by means of a timer controlled Carousel unit to a white-surface screen $1.4 \mathrm{~m}$ from $\mathrm{S}$ and 2.4 from the projector. Eye movements were recorded by means of a headmounted eye-marker camera (Mackworth \& Thomas, 1962), consisting of a 2 x $8 \mathrm{~mm}$ motion picture unit filming at a speed of 15 frames per sec and a periscope that reflects a spot of light from the cornea to the film. The film, when developed, shows the PA slides and, superimposed upon each, a bright circular spot indicating the approximate position of actual fixation. The data were analyzed frame by frame by examining the $S-R$ pairs through a film-viewer.
Procedure. On any given trial, the seven S-R pairs were presented consecutively. During this study phase, $S$ was instructed to examine the pairs in an attempt to learn them. Following a 2-sec interval, the seven stimuli were presented, with $\mathbf{S}$ attempting to recall the appropriate responses during this test phase. Slides changed every $2 \mathrm{sec}$, the intertrial interval was $2 \mathrm{sec}$, the lists were presented in each of four different random orders in an at tempt to minimize serial learning, and the session was terminated at the completion of four trials as is the standard Paivio procedure (e.g., Paivio, 1965).

Results and Discussion. An analysis of variance of correct responses revealed a statistically dependable Groups effect $(F=$ 5.10, $\mathrm{df}=3 / 56, \mathrm{p}<.005$ ), with follow-up $\mathrm{t}$ tests indicating that this could be mainly attributed to differences in learning between Group AA and each of the other three. By the fourth trial, Ss of this group had mastered approximately two of the seven pairs whereas Ss of Groups CC, CA, and AC had learned about four pairs. The lower performance of Group AA was evident on all trials, as revealed by a nonsignificant Groups by Trials interaction. Data of other similar investigations have, although not unequivocally, revealed learning proficiency to follow the order CC, CA, $\mathrm{AC}$, and AA. For example, Yuille \& Paivio (in press) reported this to be the case on the first trial; however, by trial four, only Group AA differed from the others. The learning data of the present study, therefore, are consistent with the notion that concreteness

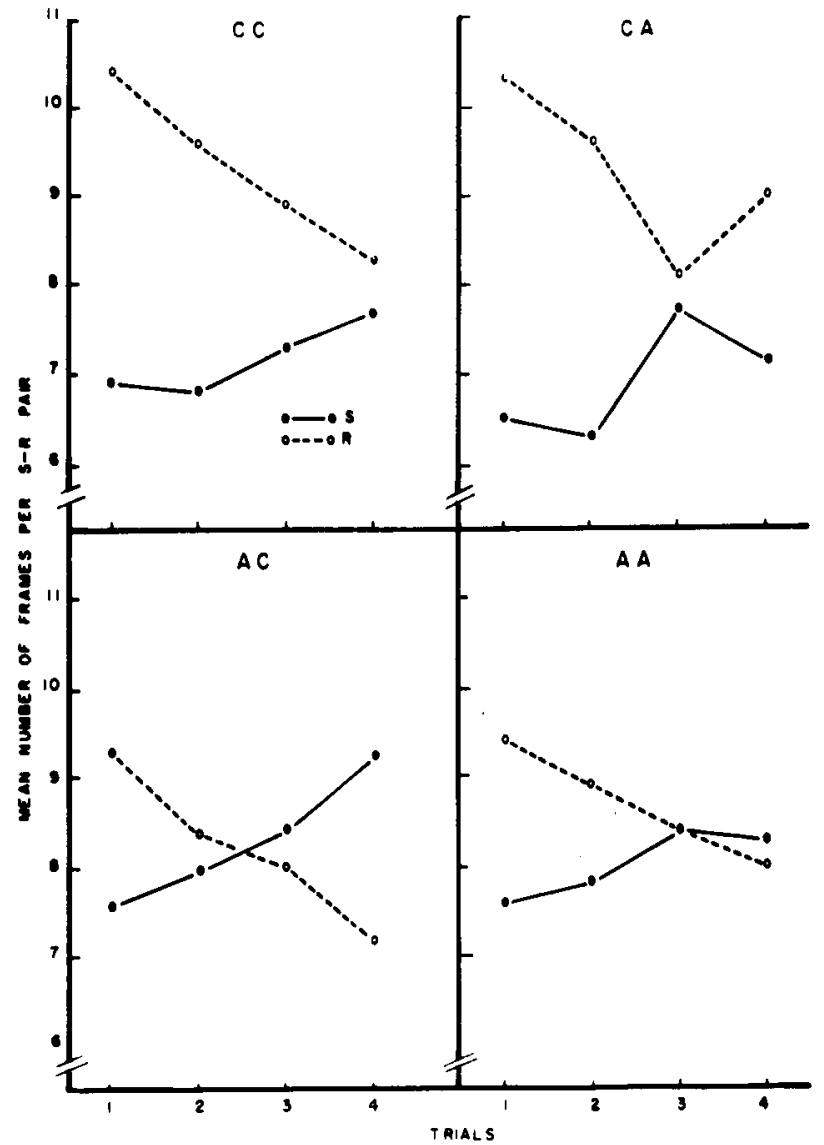

Fig. 1. Mean number of frames per S-R pair as a function of trials for the four groups of Ss. 
has a facilitating effect, but they do not demonstrate that it is a more potent variable when manipulated on the stimulus side.

An analysis of variance of mean number of eye movements per $S-R$ pair revealed a statistically dependable Trials effect $(F=$ $11.33, \mathrm{df}=3 / 168, \mathrm{p}<.001$ ), indicating a pattern of S-R to S-R-S viewing over trials, a phenomenon which has previously been interpreted as support for the two-stage notion. A lack of dependable Trials by Groups interaction indicated that this trend was characteristic of all four groups. The analysis also demonstrated a Groups effect $(F=3.21$, df $=3 / 56, p<.05)$, with t tests revealing that Groups $\mathrm{CC}$ and $\mathrm{AC}$ exhibited more overall movement than the CA and AA groups. Group AA showed least movement, a finding which is consistent with the fact that the task for these Ss was more difficult, this difficulty presumably being due to an extended response-consolidation phase. The observation that more S-R-S viewing is associated with lists having concrete responses is difficult to interpret. Should these concrete responses, however, arouse sensory images, $\mathrm{S}$ might look back to the stimulus in order to complete the mediational link.

The fixation data are presented in Fig. I where mean number of frames per S-R pair is shown as a function of trials for each group, the solid-line curves depicting fixations of the stimulus while response fixations are represented by broken lines. Analysis of variance revealed a reliable Conditions ( $S$ vs $R$ ) effect $(F=51.64$, $\mathrm{df}=1 / 392, \mathrm{p}<.001)$, indicating disproportionate response viewing for the collapsed data. A reliable Trials by Conditions effect was also obtained $(F=12.77$, df $=3 / 392, p<.001)$, and this reflects the convergence of the $S$ and $R$ functions over trials. The only other statistically dependable effect was that for Groups by Conditions $(F=11.29, \mathrm{df}=3 / 392, \mathrm{p}<.001)$, this being due to a more disproportionate viewing of the response on the part of the two groups where the stimulus was concrete. The data of Groups $\mathrm{AC}$ and $\mathrm{AA}$ are much like those obtained with nonsense syllables, and are in line with the two-stage notion. Where the stimulus is concrete, however, response viewing is definitely prolonged. This more sustained attention to the response on the part of these groups is not inconsistent with the notion that these Ss are attempting to link the response with a stimulus-produced image hence with the stimulus.

\section{REFERENCES}

MACKWORTH, N. H., \& THOMAS, E. L. Head-mounted eye-marker camera J. Opt. Soc. Amer., 1962, 52, 713-716.

McCORMACK, P. D., \& HALTRECHT, E. J. Monitoring eye movements under two conditions of presentation of paired-associate materials. Canad. J. Psychol., 1966, 20, 154-159.

NOBLE, C. E. Measurement of associative value (a), rated associations ( $\left.\mathrm{a}^{\prime}\right)$ and scaled meaningfulness $\left(\mathrm{m}^{\prime}\right)$ for the $2100 \mathrm{CVC}$ combinations of the English alphabet. Psychol. Rep., 1961, 8, 487-521.

PAIVIO, A. Abstractness, imagery and meaningfulness in paired-associate learning. J. verbal Learm. verbal Behav., 1965, 4, 32-38.

PAIVIO, A. Meaning, mediation and memory. Research Bulletin No. 48, Dept. of Psychol., Univ. of Western Ontario, 1967.

PAIVIO, A., \& YUILLE, J. C. Word abstractness and meaningfulness, and paired-associate learning in children. J. exp. Child Psychol., 1966, 4, 81-89.

PAIVIO, A., YUILLE, J. C., \& MADIGAN, S. A. Concreteness, imagery, and meaningfulness values for 925 nouns. J. exp. Psychol., 1968, 76, (Monogr. Suppl. No. 1, Part 2).

PAIVIO, A., YUILLE, J. C., \& SMYTHE, P. C. Stimulus and response abstractness, imagery, and meaningfulness, and reported mediators in paired-associate learning. Canad. J. Psychol., 1966, 20, 362-377.

UNDERWOOD, B. J., RUNQUIST, W. N., \& SCHULZ, R. W. Response learning in paired-associate lists as a function of intralist similarity. J. exp. Psychol., 1959, 58, 70-78.

YUILLE, J. C., \& PAIVIO, A. Imagery and verbal mediation instructions in paired-associate learning. J. exp. Psychol, in press. 